\title{
Acute coronary syndrome in women of reproductive age
}

This article was published in the following Dove Press journal:

International Journal of Women's Health

9 November 201।

Number of times this article has been viewed

\author{
Nazimah Idris' \\ Sharifah Sulaiha Aznal' \\ Sze-Piaw Chin' \\ Wan Azman Wan Ahmad ${ }^{2}$ \\ Azhari Rosman ${ }^{3}$ \\ Sinnadurai Jeyaindran ${ }^{4}$ \\ Omar Ismail ${ }^{5}$ \\ Robaayah Zambahari ${ }^{3}$ \\ Kui Hian Sim ${ }^{6}$ \\ 'International Medical University, \\ Seremban; ${ }^{2}$ University Malaya Medical \\ Centre, PJ; ${ }^{3}$ Institut Jantung Negara, \\ $\mathrm{KL} ;{ }^{4}$ Hospital Kuala Lumpur, KL; \\ ${ }^{5}$ Hospital Pulau Pinang; ${ }^{6} \mathrm{H}$ ospital \\ Umum Sarawak, Malaysia
}

Background: There is scarce or no data on prevalence and presentation of acute coronary syndrome (ACS) among women of reproductive age. Furthermore, whether women of reproductive age presenting with ACS have the same risk factors as men and older women is not known.

Objective: To analyze factors associated with ACS in women of reproductive age in comparison with older women and men of a similar age group.

Methodology: A total of 9702 cases of acute coronary syndrome over a 3-year period (2006-2008) from the National Cardiovascular Disease database were analyzed, with focus on women of reproductive age ( $20-<40$ years), looking into association with ethnicity, comorbid illness, and the ACS stratum. Comparison with older women (40-<60 years; Control 1) and men of similar age group (Control 2) was made and analyzed using Fisher's exact test and chi-square test when necessary.

Results: From a total of 9702 cases, 2344 (24.2\%) were women. Of these, 45 (1.9\%) were women between 20 and $<40$ years, which is significantly lower than the two controls (older women $30.8 \%$, and men of same age $6.2 \%$, respectively; $P<0.0001$ ). The distribution of ethnicity shows a similar pattern between the study group and the controls, but patients of Indian ethnicity were over-represented when compared with the Malaysian demographics of general population $(31.3 \%$ versus $7.1 \% ; P<0.0001)$. ACS in women of reproductive age was associated with diabetes mellitus in $37.8 \%$, hypertension in $40.0 \%$, and dyslipidemia in $24.4 \%$ of cases, similar to men of the same age but significantly lower than the older women $(P<0.0001)$. Smoking is not a major risk factor in the study group, where only $6.7 \%$ ever smoked, similar to older women $(6.8 \%, P=1.000)$ and significantly much less compared with men of the same age (84.1\%; $P<0.0001)$. Regarding the ACS stratum, a significantly higher percentage of women in the study group had ST-segment elevation myocardial infarction compared with older women $(P=0.0085)$ but less than that of men of similar age $(P=0.0187)$.

Conclusion: ACS is rare in women of reproductive age. Diabetes, hypertension, and Indian ethnicity were identified as important contributors.

Keywords: reproductive-aged women, comorbidities, risk factors

\section{Background}

Even though coronary heart disease is the leading cause of death for both men and women, there is scarce or no data on the prevalence and presentation of acute coronary syndrome (ACS) among women of reproductive age. Furthermore, whether women of reproductive age presenting with ACS have the same risk factors from men and older women is not known. The lack of data is probably due to the perceived low incidence
Correspondence: Sim Kui Hian Heart House, Level I, Academy Medicine Building, 210 Jalan Tun Razak 50400 Kuala Lumpur, Malaysia Email sim.kui.hian@health.gov.my 
of ACS in this group of women and that it does not constitute a major health concern.

Incidence of ACS in women of reproductive age has indeed been reported to be low. Data from a Danish cohort reported an incidence of 25 per 100,000 person years while American data reported 57 per 100000 person years. ${ }^{1,2}$ The high circulating estrogen in younger women has traditionally been thought to be cardio-protective. However, with the increasing prevalence of certain cardiovascular risk factors, particularly obesity, ${ }^{3}$ the risk of ACS in younger-aged women is expected to rise and become a significant health concern in future. Furthermore, the use of oral contraceptive pills in reproductive-aged women has been shown to double the risk of ACS. ${ }^{4}$ There is also the risk of pregnancy, and while pregnancy itself has not usually been thought to be a risk factor for ACS, there is an increased level of estrogen and progesterone in maternal circulation which increases the risk of thrombosis, which may compound other pre-existing risk factors, leading to an increased ACS risk.

Data regarding ACS among men and older women are more established. Among the risk factors identified for ACS in this group are hypercholesterolemia, hypertension, diabetes mellitus, family history of coronary artery disease (CAD), and cigarette smoking. For younger adults, especially women, it has been suggested that the risk factor profile for ACS is different. While hypercholesterolemia, family history of $\mathrm{CAD}$, and maybe cigarette smoking may be similar, systemic hypertension and diabetes mellitus may not be very prevalent in younger adults. ${ }^{5,6}$ As for the role of gender in ACS, it has been found that while women overall had a lower incidence of ACS than men, and higher prevalence of unstable angina rather than myocardial infarction, when myocardial infarction occurs in younger women, the mortality and morbidity rates are higher than men of the same age. ${ }^{7,8}$

Based on these concerns, we feel it is important to increase our understanding regarding ACS in younger women, particularly those in the reproductive aged group. We aim to identify the specific risk factors for this group, and the information obtained can be helpful in planning management strategy in these women.

\section{Methodology}

This is a retrospective analysis of all cases of ACS recorded in the National Cardiovascular Disease Registry (NCVD). The registry was drawn up by content experts in the discipline led by representatives from the Departments of Cardiology belonging to the Ministry of Health, universities, the National Heart Institute (Institut Jantung Negara (IJN)), and the Department of Medicine at Kuala Lumpur Hospital. It was designed to be compatible with international registries and to comply with guidelines issued by the Australia's National Data Elements for ACS, the Cardiology Audit and Registration Data Standards (CARDS), and the American College of Cardiology Clinical Data Standards. The full version was designed to collect detailed demographic, past medical history, clinical and procedural information, and pharmacotherapy. In-patient, 30-days and 12-months follow-up forms were included to document the progress of the patient, in particular the occurrence of any major adverse cardiovascular events following discharge from hospital. A full list of participating sites may be found at the end of the article.

\section{Patient enrolment}

The registry records any patient aged 18 years and above who is diagnosed with ACS including ST-elevation myocardial infarction (STEMI), non-STEMI, and unstable angina admitted to the participating centers. ACS is defined as the presence of at least two of the following: 1) clinical presentation, 2) electrocardiographic changes, and 3) cardiac enzyme elevation. Typical clinical presentation is defined as: typical anginal pain at rest lasting more than 20 minutes; new-onset angina of at least Canadian Cardiovascular Society grade III severity; previously diagnosed angina that has become more frequent, longer in duration, or more easily provoked; and/or acute decompensated heart failure in a patient with known ischemic heart disease. Typical electrocardiographic changes is defined as: ST-segment depression by more than $0.05 \mathrm{mV}$ in two or more contiguous leads, marked symmetrical T-wave inversion by more than $0.2 \mathrm{mV}$ in the precordial leads, new bundle branch block, and/or sustained ventricular tachycardia. Typical pattern of elevation of conventional cardiac enzymes includes creatine kinase (CK), aspartate transaminase (AST), and lactate dehydrogenase (LDH), elevated Troponin T or I, and/or elevated isoenzyme CK-MB.

After discharge, the patient will have been contacted by telephone or seen in the clinic after 30 days and after 12 months. For the purpose of the registry, any new episodes of chest pain or diagnosis of ACS within 30 days of discharge are considered recurrent episodes or complications of the index event. Symptoms that occur more than 30 days later are considered new episodes in which new event notification forms are submitted. The Medical Research and Ethics Committee waived informed consent for this national registry. 
A total of 9702 cases of acute coronary syndrome over a 3-year period (2006-2008) from the NCVD database were analyzed, with focus on the women of reproductive age (taken as women aged $20-<40$ years). There were two control groups for this analysis: Control 1 was the older aged women $(40-<60$ years old), where we intended to look at the influence of hormonal status in the development of ACS; and Control 2 was the same-aged men, to look into gender differences.

As Malaysia is a pluralistic society, we looked into the association of ACS with ethnicity, focusing on the three major ethnic groups in Malaysia, ie, Malay, Chinese, and Indian. Each ethnic group has its own ethnocultural identity, and we hypothesize these differences may have significant contribution towards developing ACS.

We studied the comorbid illness commonly associated with ACS and compared their presence in the three groups, looking for a particular trend specific to reproductiveaged women. We also looked into the ACS stratum to identify specific patterns of clinical presentation in our focus group.

For all the factors identified, comparisons with older women $(40-<60$ years) and men of similar age were made and analyzed with Fisher's exact test and chi-square test, when necessary, using SPSS software (version 17; SPSS Inc., Chicago, IL). Level of significance was determined at $P<0.05$ at $95 \%$ confidence interval (CI).

\section{Results}

Over the 3-year period, 9702 cases of ACS were recovered from the registry. A total of 7358 (75.8\%) were men, and $2344(24.2 \%)$ were women. Of these, 45 were from the reproductive-age group, which is $1.9 \%$ of all women or $0.5 \%$ overall. Older women (Control 1) recorded 721 cases $(30.8 \%$ of all women or $7.4 \%$ overall), while men of the same age (Control 2) recorded 454 cases ( $6.2 \%$ of all men, or $4.7 \%$ ), both of which are significantly higher than the study group.

The distribution of ethnicity shows no significant differences between the study group and the two control groups $(P>0.05)$. From the results, it seemed that the percentage of patients from Indian ethnicity were significantly higher in all three groups when compared with the Malaysian demographics of general population $(31.1 \%, 33.0 \%$, and $25.3 \%$ versus $7.1 \% ; P<0.0001)$. Unfortunately the statistics for ethnic Indians from the specific age groups were not available for more direct comparison, and hence the significance of this finding cannot be determined. ${ }^{9}$ The results are shown in Table 1.
Table I Distribution of events of acute coronary syndrome and ethnicity

\begin{tabular}{llll}
\hline Ethnicity & $\begin{array}{l}\text { Study } \\
\mathbf{n = 4 5}\end{array}$ & $\begin{array}{l}\text { Control I } \\
\mathbf{n = 7 2 I}\end{array}$ & $\begin{array}{l}\text { Control 2 } \\
\mathbf{n = 4 5 4}\end{array}$ \\
\hline Malay & 18 & 347 & $2 \mathrm{II}$ \\
$(\%)$ & $(40.0)$ & $(48.1)$ & $(46.5)$ \\
Chinese & 10 & 105 & 74 \\
$(\%)$ & $(22.2)$ & $(14.6)$ & $(16.3)$ \\
Indian & 14 & 238 & 115 \\
$(\%)$ & $(31.1)$ & $(33.0)$ & $(25.3)$ \\
Other & 3 & 24 & 43 \\
$(\%)$ & $(6.7)$ & $(3.3)$ & $(9.5)$ \\
Missing & 0 & 7 & 11 \\
$(\%)$ & & $(1.0)$ & $(2.4)$ \\
\hline
\end{tabular}

The prevalence of diabetes mellitus, hypertension, and dyslipidemia in women of reproductive age with ACS was similar to men of the same age but significantly lower than the older women $(P<0.0001)$. Smoking is not a major risk factor in the study group, where only $6.7 \%$ ever smoked, similar to older women $(6.8 \% ; P=1.000)$ and significantly much less compared with men of the same age $(84.1 \%$; $P<0.0001)$. With regards to the family history, the prevalence did not differ significantly between the study and the two control groups $(P>0.05)$. These findings are summarized in Table 2.

Regarding the ACS stratum, interestingly we found the study group to be more likely to have STEMI rather than non-STEMI or unstable angina $(51.1 \%$ versus $20.0 \%$ and $28.9 \%$, respectively). Significantly more women in the study group had STEMI compared with older women $(P=0.0085)$ but less than that of men of similar age $(P=0.0187)$, as shown in Table 3.

Table 2 The prevalence of comorbid illnesses in acute coronary syndrome groups

\begin{tabular}{|c|c|c|c|c|c|}
\hline Comorbidity & $\begin{array}{l}\text { Study } \\
\mathrm{n}=45\end{array}$ & $\begin{array}{l}\text { Control I } \\
n=72 I\end{array}$ & $P$ value & $\begin{array}{l}\text { Control } 2 \\
n=454\end{array}$ & $P$ value \\
\hline $\begin{array}{l}\text { Diabetes } \\
\text { mellitus } \\
(\%)\end{array}$ & $\begin{array}{l}14 \\
(37.8)\end{array}$ & $\begin{array}{l}440 \\
(61.0)\end{array}$ & $<0.0001$ & $\begin{array}{l}101 \\
(22.2)\end{array}$ & $>0.05$ \\
\hline $\begin{array}{l}\text { Hypertension } \\
(\%)\end{array}$ & $\begin{array}{l}18 \\
(40.0)\end{array}$ & $\begin{array}{l}538 \\
(74.6)\end{array}$ & & $\begin{array}{l}146 \\
(32.1)\end{array}$ & \\
\hline $\begin{array}{l}\text { Dyslipidemia } \\
\text { (\%) }\end{array}$ & $\begin{array}{l}11 \\
(24.4)\end{array}$ & $\begin{array}{l}256 \\
(35.5)\end{array}$ & & $\begin{array}{l}100 \\
(22.0)\end{array}$ & \\
\hline \multicolumn{6}{|l|}{ Smoking } \\
\hline $\begin{array}{l}\text { Never } \\
\text { (\%) } \\
\text { Ever } \\
(\%)\end{array}$ & $\begin{array}{l}42 \\
(93.3) \\
3 \\
(6.7)\end{array}$ & $\begin{array}{l}639 \\
(88.6) \\
49 \\
(6.8)\end{array}$ & 1.000 & $\begin{array}{l}54 \\
(11.9) \\
382 \\
(84.1)\end{array}$ & $<0.0001$ \\
\hline $\begin{array}{l}\text { Family history } \\
\text { (\%) }\end{array}$ & $\begin{array}{l}7 \\
(15.6)\end{array}$ & $\begin{array}{l}106 \\
(14.7)\end{array}$ & $>0.05$ & $\begin{array}{l}101 \\
(22.2)\end{array}$ & $>0.05$ \\
\hline
\end{tabular}


Table 3 The ACS stratum

\begin{tabular}{lllll}
\hline ACS stratum & $\begin{array}{l}\text { Study } \\
\mathbf{n}=\mathbf{4 5}\end{array}$ & $\begin{array}{l}\text { Control I } \\
\mathbf{n = 7 2 I}\end{array}$ & $\boldsymbol{P}$ value & $\begin{array}{l}\text { Control 2 } \\
\mathbf{n}=\mathbf{4 5 4}\end{array}$ \\
\hline STEMI & 23 & 227 & $\mathbf{P}$ value \\
$(\%)$ & $(51.1)$ & $(31.5)$ & $\mathbf{P}=0.0085$ & $(69.2)$ \\
Non-STEMI & 9 & 177 & 58 \\
$(\%)$ & $(20.0)$ & $(24.5)$ & $(12.8)$ \\
UA & 13 & 317 & 82 \\
$(\%)$ & $(28.9)$ & $(44.0)$ & $(18.1)$ \\
\hline
\end{tabular}

Abbreviations: ACS, acute coronary syndrome; STEMI, ST-elevation myocardial infarction; UA, unstable angina.

\section{Discussion}

Our study highlighted the following points: ACS is rare in women of reproductive age; comorbid illnesses and Indian ethnicity were potentially important contributors; and due to higher rate of STEMI, mortality risk is higher.

Our findings concur with the available data that ACS in reproductive-aged women is rare, and among the most likely reason is the protective effect of high levels of circulating estrogen in this group of women. The cardio-protective mechanisms of estrogen can be exerted via vasodilatation, vascular remodeling, angiogenesis, endothelial cell proliferation, hemostatic and thrombolytic functions, lipid metabolism, and antioxidant effects. ${ }^{10}$ Losordo et al demonstrated significant association between estrogen receptor expression and absence of atherosclerosis in premenopausal women. In 12 normal arteries, estrogen receptor expression was shown immunohistochemically in $10(83.3 \%)$, whereas in 5 of 6 atherosclerotic arteries, no evidence of estrogen receptor expression was observed. ${ }^{11}$ Older women with lower estrogen levels and men who do not enjoy similar cardioprotection recorded significantly higher incidence of ACS on our analysis.

In regards to risk factors for ACS, we found ethnic origin appeared to be important where patients of Indian ethnicity seemed particularly at risk, even at a younger age. The INTERHEART investigators in a detailed analysis of 15,152 cases and 14,820 age-matched controls from 52 countries found the incidence of ACS in South Asian people to be higher than average and they also tend to present earlier. The incidence of ACS in South Asian women aged $<40$ years was found to be $3.9 \%$, higher than the $2.3 \%$ average in that study and the $0.5 \%$ from our study. While it seemed that South Asian ethnicity is an absolute risk factor, further analysis revealed that people of South Asia had higher levels of ACS risk factors compared with the participants from the rest of the world, particularly a higher burden of metabolic risk factors, a higher prevalence of tobacco use, and lower rates of protective factors (physical activity, daily intake of fruits and vegetables), ${ }^{12,13}$ suggesting that those risk factors, and not ethnicity per se, is primarily responsible for their higher rates of ACS.

We think this suggestion could be applicable to our patients as well. While the NCVD Registry did not specifically provide data on risk factors for each ethnic group, the data from the Third Malaysian National Health Morbidity Survey (NHMS III) showed that the Indian ethnic group has the highest prevalence of diabetes mellitus compared with the other two major ethnic groups (19.9\% versus $11.9 \%$ and $11.4 \%$ for Malay and Chinese groups respectively), and this inevitably contributed to their increased ACS risk. ${ }^{14}$ Ramachandran et al has also demonstrated high incidence of glucose intolerance in Asian-Indian subjects with ACS, where $83.5 \%$ of the subjects either had diabetes or impaired glucose tolerance/impaired fasting glucose..$^{15,16}$

Among the modifiable risk factors, as expected, we found the reproductive-aged women to have less comorbidities than older women, but nonsignificantly higher than the same-aged men. The presence of these risk factors may potentially negate the cardio-protectivity of estrogen against ACS.

Data from NHMS III found the national prevalence for hypertension is $32.2 \%$, diabetes mellitus $11.6 \%$, and dyslipidemia $7.1 \%$. This is reflected in our study group, which shows hypertension to be the most common comorbid illness associated with ACS. With regards to diabetes mellitus, although the national prevalence was lower than hypertension, patients with ACS had higher prevalence compared with the general population (31.1 versus $11.6 \%$ ), indicating the strong association of diabetes to ACS. Similarly for dyslipidemia, reproductive-aged women with ACS recorded $24.4 \%$ prevalence compared with the national prevalence of $7.1 \%$. It is of particular concern that females have significantly higher prevalence of hypercholesterolemia compared with males (8.0 versus $6.3 \%$, respectively).

With regards to smoking, even though only $6.7 \%$ of the women in our study group smoked, compared with $84.1 \%$ of men, this rate is still higher than the national average 
for female smokers at $2.5 \%$, indicating the importance of smoking as a risk factor. Strong association between smoking and ACS has been repeatedly established, particularly in younger patients. ${ }^{5,17}$ Milionis et al reported an odds ratio of 4.46 (95\% confidence intervals [CI]: 2.30-8.66; $P<0.001$ ) for smoking in 136 patients compared with ageand sex-matched controls. ${ }^{17}$

Other than risk factors discussed above, reproductiveaged women have at least two more additional risk factors for ACS, namely the use of hormonal contraception and pregnancy. The use of oral contraceptive pills in reproductive-aged women has been shown to double the risk of ACS, while pregnancy increased it further to 3-4 times higher. ${ }^{2,4,18}$ In these patients the contribution of hypertension and diabetes to ACS were significant too.

Probably one the most important findings in this analysis is that reproductive-aged women recorded significantly more STEMI than non-STEMI when compared with older women, although still significantly less than same-aged men.

Overall, women are acknowledged to be less likely to present with STEMI than men. A large RCT, GUSTO IIb reported $27.2 \%$ STEMI in women versus $37.0 \%$ in men. However, in the subgroup of women who had STEMI, the age-adjusted prognosis was marginally worse than men with STEMI. ${ }^{17}$ In another analysis from a massive database that includes 1658 hospitals in the United States, the mortality rate among younger women with myocardial infarction is found to be significantly higher than men. ${ }^{18}$ Therefore, it seems that while the prevalence of ACS in reproductive-aged women is low, for those with ACS, their prognosis is worse than older women or same-aged men, probably related to the higher incidence of STEMI in this group. It raises the question of whether younger women with ACS have some particularly strong risk factor, or lack of protective factor normally present in younger women without ACS. In this regard, variations in the estrogenregulated gene expressions and forms of estrogen receptors, including the one with anti-estrogen effect, may be contributory. ${ }^{19}$ Early onset of ACS seems to be associated with the presence of combined risk factors. In this panel, we may include acquired common risk factors for ACS, in particular smoking and possibly gene variant associated to thrombotic disorders such as MTHFR C677T gene variant and ACE del $\backslash$ del genotype. However, further studies are needed to confirm this association. ${ }^{20}$

There are several limitations in our study. Firstly, the number of subjects in the study group was small, only 45 out of a total of 9702 cases, and this has limited our ability to make a definitive conclusion. Also, being retrospective, certain important data are not available for cross-analysis. Most notable is the mortality data that was not age and gender subcategorized. Therefore, although our study group has a higher prevalence of STEMI, we were unable to show that the actual mortality rate in this group is higher than the controls due to this limitation. For similar reasons, we were also unable to stratify our analysis by ethnicity. While it would have been interesting to know how many of these patients are without risk factors, the database unfortunately did not age- and gender-specify the information and hence it is not available for discussion. Also, comparisons with the general population were made based on the available adult data across the age groups, and not age specific, hence limiting the significance of the comparisons. On the other hand, the NCVD is the most comprehensive available database on ACS, with data contributed by all major hospitals in the country, and therefore is without doubt a good representation of the actual state of the disease in the country.

The findings from our analysis can be used in several ways. Most important is to recognize the high prevalence of risk factors in reproductive-aged women who develop ACS and that the cardio-protective effects of estrogen is somewhat negated by the strong association with the comorbidities. It is also important to realize that ACS in younger women differs from older women where STEMI is more common and consequently mortality risk is higher. Although the outcome and impact of current treatment strategies are beyond the scope of this paper, the data presented should help to increase our awareness of the more likely nature of the ACS presenting in young women and would help strategize the management accordingly, possibly in regards to the urgency in commencing fibrinolytic therapy for this group.

\section{Participating sites}

The ACS database was piloted in 6 coronary care units (CCUs) on January 1, 2006. The CCUs were based in IJN, KL Hospital, University Malaya Medical Centre, Hospital Pulau Pinang, Hospital Sultanah Aminah, JB and Hospital Umum Sarawak. One month later, following minor adjustments and review of the work-flow process, the Computer Recovery Facility (CRF) was approved for nationwide use. Five Ministry of Health general hospitals around the country joined the 6 pilot centers. They are: Hospital Tuanku Fauziah Kangar, Perlis; Hospital Tuanku Ja'afar Seremban, Negeri Sembilan; Hospital Sultanah Bahiyah Alor Setar, 
Kedah; Hospital Raja Perempuan Zainab II Kota Bahru, Kelantan; and Hospital Tengku Ampuan Afzan Kuantan, Pahang. In addition, the medical department of Hospital Umum Sarawak also participated. More hospitals have joined NCVD since 2006. They are: Ipoh Hospital, Perak; Queen Elizabeth Hospital, Sabah; Seberang Jaya Hospital; Hospital Sultanah Nur Zahirah, Terengganu; Hospital Tengku Ampuan Rahimah, Klang Selangor; and Hospital Besar Melaka.

\section{Disclosure}

The authors report no conflicts of interest in this work.

\section{References}

1. Nielsen KM, Foldspang A, Larsen ML, Gerdes LU, Rasmussen S, Faergeman O. Estimating the incidence of the acute coronary syndrome: data from a Danish cohort of 138290 persons. Eur J Cardiovasc Prev Rehabil. 2007;14:608-614.

2. Petitti DB, Sidney S, Quesenberry CP, Bernstein A. Incidence of stroke and myocardial infarction in women of reproductive age. Stroke. 1997; 28:280-283.

3. Mokdad AH, Serdula MK, Dietz WH, Bowman BA, Marks JS, Koplan JP. The spread of the obesity epidemic in the United States, 1991-1998. JAMA. 1999;282:1519-1522.

4. Tanis BC, van den Bosch MA, Kemmeren JM, et al. Oral contraceptives and the risk of myocardial infarction. $N$ Engl J Med. 2001;345: 1787-1793.

5. Uhl GS, Farrell PW. Myocardial infarction in young adults: risk factors and natural history. Am Heart J. 1983;105:548-553.

6. Weinberger I, Rotenberg Z, Fuchs I, Sagy A, Friedmann J, Agmon J. Myocardial infarction in young adults under 30 years: risk factors and clinical course. Clin Cardiol. 1987;10:9-15.

7. Hochman JS, Tamis JE, Thompson TD, et al. Sex, clinical presentation and outcome in patients with acute coronary syndromes. Global Use of Strategies to Open Occluded Coronary Arteries in Acute Coronary Syndrome IIb Investigators. N Eng J Med. 1999;341:226-232.

8. Vaccarino V, Parsons L, Every NR, Barron HV, Krumholz HM. Sex-based differences in early mortality after myocardial infarction. N Eng J Med. 1999;341:217-225.
9. Index Mundi. Malaysia - demographics. Available from: http://www. indexmundi.com/malaysia/ethnic_groups.html. Accessed December 10, 2010.

10. Mendelsohn ME, Karas RH. The protective effects of estrogen on the cardiovascular system. $N$ Engl J Med. 1999;340:1801-1811.

11. Losordo DW, Kearney M, Kim EA, Jekanowsky J, Isner JM. Variable expression of the estrogen receptor in normal and atherosclerotic coronary arteries of premenopausal women. Circulation. 1994;89: $1501-1510$.

12. Yusuf S, Hawken S, Ounpuu S, et al. Effect of potentially modifiable risk factors associated with myocardial infarction in 52 countries (the INTERHEART study): case-control study. Lancet. 2004;364: 937-952.

13. Goyal A, Yusuf S. The burden of cardiovascular disease in the Indian subcontinent. Indian J Med Res. 2006;124:235-244.

14. Secretariat National Institutes of Health, Ministry of Health, Malaysia. Available from: http://en.wikipedia.org/wiki/Demographics_of_Malaysia. Accessed December 20, 2010.

15. Ramachandran A, Chamukuttan S, Immaneni S, et al. High incidence of glucose intolerance in Asian-Indian subjects with acute coronary syndrome. Diabetes Care. 2005;28(10):2492-2496.

16. Teo KK, Ounpuu S, Hawken S, et al. Tobacco use and risk of myocardial infarction in 52 countries in the INTERHEART study: a case-control study. Lancet. 2006;368(9536):621-622.

17. Milionis HJ, Kalantzi KJ, Papathanasiou AJ, Kosovitsas AA, Doumas MT, Goudevenos JA. Metabolic syndrome and risk of acute coronary syndromes in patients younger than 45 years of age. Coron Artery Dis. 2007;18:247-252.

18. James AH, Jamison MG, Biswas MS, Brancazio LR, Swamy GK, Myers ER. Acute myocardial infarction in pregnancy: a United States population-based study. Circulation. 2006;113:1564-1571.

19. Inoue $\mathrm{S}$, Hoshino $\mathrm{S}$, Miyoshi $\mathrm{H}$, et al. Identification of a novel isoform of estrogen receptor, a potent inhibitor of estrogen action, in vascular smooth muscle cells. Biochem Biophy Res Commun. 1996;219: 766-772.

20. Pierpaolo Di Micco, Giovanni Rossano, Maria Blasich, et al. Association of thrombophilic gene variant with smoking as risk factors for early onset of acute coronary syndrome. Open Atherosclerosis Thrombosis $J$. 2009;2:42-44
International Journal of Women's Health

\section{Publish your work in this journal}

The International Journal of Women's Health is an international, peerreviewed open-access journal publishing original research, reports, reviews and commentaries on all aspects of women's healthcare including gynecology, obstetrics, and breast cancer. Subject areas include: Chronic conditions (migraine headaches, arthritis, osteoporosis);

\section{Dovepress}

Endocrine and autoimmune syndromes; Sexual and reproductive health; Psychological and psychosocial conditions. The manuscript management system is completely online and includes a very quick and fair peer-review system. Visit http://www.dovepress.com/ testimonials.php to read real quotes from published authors. 